\title{
SOSIALISASI PENGADAAN TANAH BAGI PEMBANGUNAN UNTUK KEPENTINGAN UMUM DI DESA MERANTI UTARA KECAMATAN PINTU POHAN MERANTI KABUPATEN TOBA
}

\author{
Uswatun Hasanah ${ }^{1 *}$, Elyani ${ }^{2}$, Khamo Waruwu ${ }^{3}$, Ahmad Yudhira ${ }^{4}$ \\ 1,4Program Studi Akuntansi, Fakultas Ekonomi dan Bisnis, Universitas Tjut Nyak Dhien \\ ${ }^{2}$ Program Studi Hukum, Fakultas Hukum, Universitas Tjut Nyak Dhien \\ ${ }^{3}$ Program Studi Manajemen, Fakultas Ekonomi Dan Bisnis, Universitas Tjut Nyak Dhien \\ ${ }^{*}$ Coresponding-Author : uswah.hana@yahoo.com
}

\begin{abstract}
ABSTRAK. Kebutuhan akan listrik semakin bertambah setiap tahunnya, untuk itu harus diiringi dengan pertumbuhan pembangkit listrik agar mampu melayani seluruh kebutuhan masyarakat. Dalam hal ini pemerintah telah memulai pembangunan pembangkit listrik tenaga Air Asahan (PLTA Asahan). Dalam pelaksanaannya diperlukan area yang menjadi lokasi pembangunan khususnya untuk pembuatan lahan tapak Tower T/L 150 KV PLTA Asahan III- Gardu Induk Simangkuk. Untuk itu harus dilakukan sosialisasi kepada masyarakat terdampak agar proses pembangunan dapat berjalan dengan lancar. Beberapa kendala yang dihadapi dalam proses pembangunan ini yaitu masih kurangnya pemahaman masyarakat akan pentingnya pembangunan tapak Tower T/L 150 KV PLTA Asahan III untuk memenuhi kepentingan masyarakat luas. Masyarakat masih ada yang belum mau melepaskan hak akan tanahnya karena berbagai alasan diantaranya harga yang ditawarkan tidak sesuai, ketakutan kehilangan mata pencaharian jika pindah ketempat lain serta adanya sengketa tanah di dalam kepemilikan hak atas tanah tersebut. Tim Pengabdian masyarakat Universitas Tjut Nyak Dhien ikut serta dalam membantu kegiatan sosialisasi kepada masyarakat dengan cara membuka konsultasi baik dari segi hukum, sosial ekonomi dan manajemen keuangan. Selain itu Tim pengabdian masyarakat juga melakukan pendekatan kepada masyarakat melalui pendekatan personal, budaya, nonformal serta kearifan lokal, dan juga melakukan pendekatan kepada tokoh-tokoh masyarakat setempat untuk memberikan pemahaman kepada masyarakat akan arti pentingnya pembangunan ini. Hasil dari sosialisasi tersebut adalah masyarakat memahami dengan baik maksud dari tujuan penyediaan tanah bagi kepentingan umum, Proses pengalihan tanah dari masyarakat untuk pengadaan lahan tapak Tower T/L 150 KV PLTA Asahan III- Gardu Induk Simangkuk di desa Meranti utara berjalan dengan baik.
\end{abstract}

Kata Kunci: pengadaan tanah untuk pembangunan, kepentingan umum

ABSTRACT. The need for electricity is increasing every year, for that it must be accompanied by the growth of power plants in order to be able to serve all the needs of the community. In this case, the government has started the construction of the Asahan Air power plant (PLTA Asahan). In its implementation, it is necessary to have an area that will become the location of development, especially for the construction of the T/L 150 KV PLTA Asahan III-Simangkuk PLTA Tower site. For this reason, socialization to affected communities must be carried out so that the development process can run smoothly. Some of the obstacles faced in the development process, namely the lack of public understanding of the importance of the construction of the T/L $150 \mathrm{KV}$ PLTA Asahan III Tower site to meet the interests of the wider community. There are still people who do not want to give up their land rights for various reasons including the price offered is not appropriate, the fear of losing their livelihood if they move to another place and the existence of land disputes in the ownership of the land rights. The Tjut Nyak Dhien University Community Service Team participated in helping outreach activities to the community by opening consultations in terms of legal, socio-economic and financial management. In addition, the community service team also approached the community through personal, cultural, non-formal approaches and local 
wisdom, and also approached local community leaders to provide an understanding to the community about the importance of this development. The result of the socialization is that the community understands well the purpose of providing land for the public interest. The process of transferring land from the community for land acquisition for Tower T/L 150 KV PLTA Asahan III - Simangkuk Substation in North Meranti village is going well.

Keywords: land acquisition for development, public interest

\section{PENDAHULUAN}

Banyaknya permasalahan yang timbul akibat dari pelepasan tanah untuk pembangunan masih menjadi polemik di Indonesia. Permasalahan ini hingga saat sekarang masih terus berlangsung. Banyak dari pembangunan infrastruktur yang waktu pengerjaannya mundur dari jadwal yang telah ditetapkan yang notabene diakibatkan karena menunggu kegiatan pelepasan hak tanah selesai dilakukan. Kendala pelepasan hak tanah ini akhirnya menjadi penyebab utama gagalnya pembangunan. Padahal problem dari pelepasan hak tanah ini sudah diatur oleh Undang-undang yaitu UU no. 2 tahun 2012 serta PP Nomor 36 Tahun 2005 (Sony, 2014).

Beberapa penelitian yang pernah dilakukan dalam kaitannya dengan pembebasan hak atas tanah adalah (Irawan, 2014) yang membahas tentang pembebasan hak tanah Waduk Pluit Jakarta dimana terjadi banyak kendala dalam pembebasan lahan pembangunannya, kendala utama adalah kurangnya pemahaman masyarakat akan pentingnya pembangunan. Untuk itu sosialisasi dalam hal pembebasan tanah ini sangat urgen untuk dilakukan ditambah lagi teknik pendekatan yang dilakukan ke warga kurang tepat hingga terjadilah permasalahan-permasalahan yang timbul sesudahnya. Permasalahan sosialisasi ini juga dibahas oleh (Rachmawati \& Handoyo, 2014) yang mengatakan inti masalah dari pembebasan lahan adalah sosialisasi door to door yang dilakukan oleh pihak pengadaan dan harga yang disepakati tidak sesuai. Permasalahan lain yaitu (Mengi, 2021) yang membahas tentang pelepasan hak tanah untuk pembangunan jalan Tol Manado-Bitung dengan inti masalah adalah harga ganti rugi tidak sesuai serta kurangnya komunikasi antara pihak pengadaan dengan masyarakat terdampak. Masalah harga ganti rugi yang kurang sesuai ini juga sudah pernah terjadi pada tahun-tahun sebelumnya antara lain (Wirabrata \& Surya, 2011), (Lova, 2016), dan (Wibowo et al., 2021).

Dari hasil di atas pengadaan lahan untuk proyek pembangunan masyarakat umum masih menjadi isu mendasar dalam mempercepat penataan Prasarana di Indonesia. Hasil kajian Komite Percepatan Penyediaan Infrastruktur Prioritas (KPPIP) menyatakan pelepasan lahan merupakan masalah kedua yang paling penting sesudah penataan dan kesiapan. Meskipun Undang-Undang Nomor 2 Tahun 2012 tentang penyediaan Tanah untuk Pembangunan bagi kebutuhan masyarakat Umum telah disahkan, namun masih ada warga yang tidak bersedia membebaskan lahannya untuk pembangunan umum (Sidauruk, 2018).

Untuk meminimalisir permasalahan dalam penyediaan tanah untuk keperluan umum maka kami dari tim pengabdian masyarakat ikut membantu sosialisasi tentang UU nomor 2 tahun 2012 tentang penyediaan tanah untuk keperluan umum. Sosialisasi ini dilakukan untuk pengadaan tanah lahan tapak Tower T/L 150 KV PLTA Asahan III- GI simangkuk di desa Maeranti utara. Kami selaku tim pengabdian masyarakat ikut membantu kelancaran untuk pengadaan tapak tower PLTA asahan III - Gl simangkuk. Selain itu kami juga membantu untuk mendapatkan kepercayaan masyarakat untuk kesediaannya melepaskan hak atas tanahnya dengan ganti rugi demi kelancaran pembuatan PLTA, dan juga membantu masyarakat dalam memberikan masukan dan ide pengelolaan dampak hasil pelepasan hak tanah. 
Berdasarkan UU Pasal 1 No 3, PP Nomor 65 Tahun 2006 maka dapat diutarakan bahwa Penyediaan Tanah merupakan aktivitas untuk memperoleh lahan dengan solusi membayarkan kompensasi pada yang melepaskan atau menyerahkan lahan, bangunan, yang ditanam dan bendabenda yang berhubungan dengan lahan. Sedangkan penyediaan tanah bagi kepentingan masyarakat dapat ditelaah berdasarkan Perpres 65 Tahun 2006 yang mencantumkan makna dari definisi dari kepentingan umum yaitu:

1. Jalan umum dan jalan tol, rel kereta api (di atas tanah, di ruang atas tanah, ataupun diruang bawah tanah), saluran air minum/air bersih, saluran pembuangan air dan sanitasi;

2. Waduk, bendungan, bendungan irigasi dan bangunan pengairan lainnya;

3. Pelabuhan, bandar udara, stasiun kereta api, dan terminal;

4. Fasilitas keselamatan umum, seperti tanggul penanggulangan bahaya banjir, lahar, dan lainlain;

5. Tempat pembuangan sampah;

6. Cagar alam dan cagar budaya;

7. Pembangkit, transmisi, distribusi tenaga listrik

Penyediaan tanah sebagaimana dimaksud dalam Pasal 1 No 2 UU Nomor 2 Tahun 2012 adalah perbuatan memberikan lahan dengan menyerahkan imbalan yang sesuai dan wajar kepada pihak yang memiliki hak. Pembayaran seyogianya dimaksud pada Pasal 1 angka 10 merupakan imbalan yang sesuai dan wajar bagi pihak yang sah dalam prosedur perolehan lahan. Selanjutnya, penyediaan tanah adalah seluruh tindakan untuk memperoleh tanah dengan menyerahkan pembayaran kepada orang-orang yang memberikan kebebasan atau menyerahkan lahan, bangunan, yang ditanam, serta barang-barang yang diidentifikasi dengan lahan atau dengan pencabutan hak-hak atas lahan.

Beberapa permasalahan yang Tim dapatkan dari survei awal yang dilakukan dengan cara mewawancarai beberapa pemilik tanah adalah adanya kekhawatiran ganti rugi yang kurang layak, lahan yang ditempati dan diolah oleh warga sudah sangat lama sehingga untuk melepaskannya sangat berat, kekhawatiran apabila pindah lahan tidak menghasilkan seperti di tanah yang akan dilepaskan, lahan yang terdampak merupakan warisan yang belum dibagi, adanya kekhawatiran dari pemilik tanah bahwa uang yang diterima akan habis begitu saja, dan alasan lainnya yaitu mengapa pembangunan harus dilakukan diwilayahnya mengapa tidak di tempat lain saja. Serta masyarakat tidak merasakan dampak langsung dari pembangunan hingga muncul persepsi bahwa meskipun adanya pembangunan hanya orang yang memiliki uang banyaklah yang menikmatinya, sedangkan masyarakat hanya begitu-begitu saja tanpa ada perubahan.

\section{ANALISIS PERMASALAHAN}

Mengacu dari hasil survey awal diatas maka inti dari permasalahan pelepasan tanah adalah:

1. Kurangnya pemahaman masyarakat tentang pembangunan untuk kepentingan umum

2. Persepsi yang muncul dimasyarakat tentang penggantian hak atas tanah merupakan persepsi yang salah

3. Masih adanya perselisihan tanah warisan yang belum dibagi

4. Minimnya pemahaman masyarakat tentang pengelolaan keuangan

\section{SOLUSI YANG DITAWARKAN}

Mengacu pada masalah yang ada, maka beberapa solusi yang kami tawarkan adalah sebagai berikut: 
1. Mengenai pemahaman masyarakat tentang pembangunan untuk kepentingan umum maka dilakukan soalisasi dan musyawarah penetapan penyelesaian teknis terhadap tanah, bangunan, dan atau tanaman yang dikuasai masyarakat dikawasan hutan terdampak pembangunan tapak tower, dengan pembicara perwakilan MUSPIKA, dan perwakilan pihak PLN yang membahas seputar pembangunan Tower untuk pentingan umum.

2. Untuk persepsi masyarakat masalah ganti rugi diadakan musyawarah dan tanya jawab kepada masyarakat setelah dilaksanakannya pemberian materi tentang pentingnya pembangunan ini.

3. Sedangkan penyelesaian permasalah perselisihan tanah, akan dipanggil tokoh masyarakat untuk memidiasi, namun apabila tidak memiliki titik temu maka akan diselesaikan dipengadilan.

4. Minimnya pemahaman masyarakat tentang pengelolaan keuangan maka kami membuka konsultasi personal untuk mengatasi hal tersebut.

\section{Pelaksaan Kegiatan}

Untuk melaksanakan kegiatan tersebut maka kami melaksanakan beberapa tahapan yaitu:

Tahap I: Mendatangi perangkat desa, tokoh desa, pihak keamanan untuk membahas tentang lokasi, waktu, serta pihak yang di undang dalam kegiatan musyawarah. Menyusun dokumendokumen yang dibutuhkan, serta beberapa materi yang akan disampaikan terkait dengan budaya, kearifan lokal, serta pemahaman tentang kepentingan umum.

Tahap II: Tahap pelaksanaan musyawarah diadakan di balai desa dengan mengundang pemilik tanah terdampak, KJPP, camat, kades, sekdes, babinsa, kanit intel, PLN, kapolsek, PT SI, dan pihak-pihak yang terkait lainnya.

Tahap III: Sosialisasi personal dengan membuka konsultasi untuk menambah pemahaman apabila ada yang masih kurang berkenan serta membuka konsultasi sosial ekonomi dan keuangan.

Tahap IV: Bagi masyarakat yang masih belum mau menerima hasil mufakat akan dilaksanakan sosialisasi door to door dengan didampingi tokoh masyarakat.

Pengabdian ini dilaksanakan dengan metode sosialisasi berupa ceramah dan musyawarah kepada masyarakat yang terdampak pengadaan tanah lahan tapak Tower T/L 150 KV PLTA Asahan III - Gardu Induk Simangkuk di desa Meranti utara. Adapun mitra pada pengabdian ini adalah PT. Surveyor Indonesia yang bekerja sama dengan PT. PLN (Persero) unit pembangunan Pembangkit Sumatera. Pada kegiatan ini kami sebagai pembantu pendamping untuk menyukseskan kegiatan pelepasan hak atas tanah dari masyarakat untuk kepentingan umum yaitu pengadaan tapak tower untuk pembangkit listrik. Waktu dan pelaksanaan kegiatan dilaksanakan pada tanggal 29 Juli 2021 di desa Meranti Utara, Kecamatan Pintu Pohan Meranti, Kabupaten Toba.
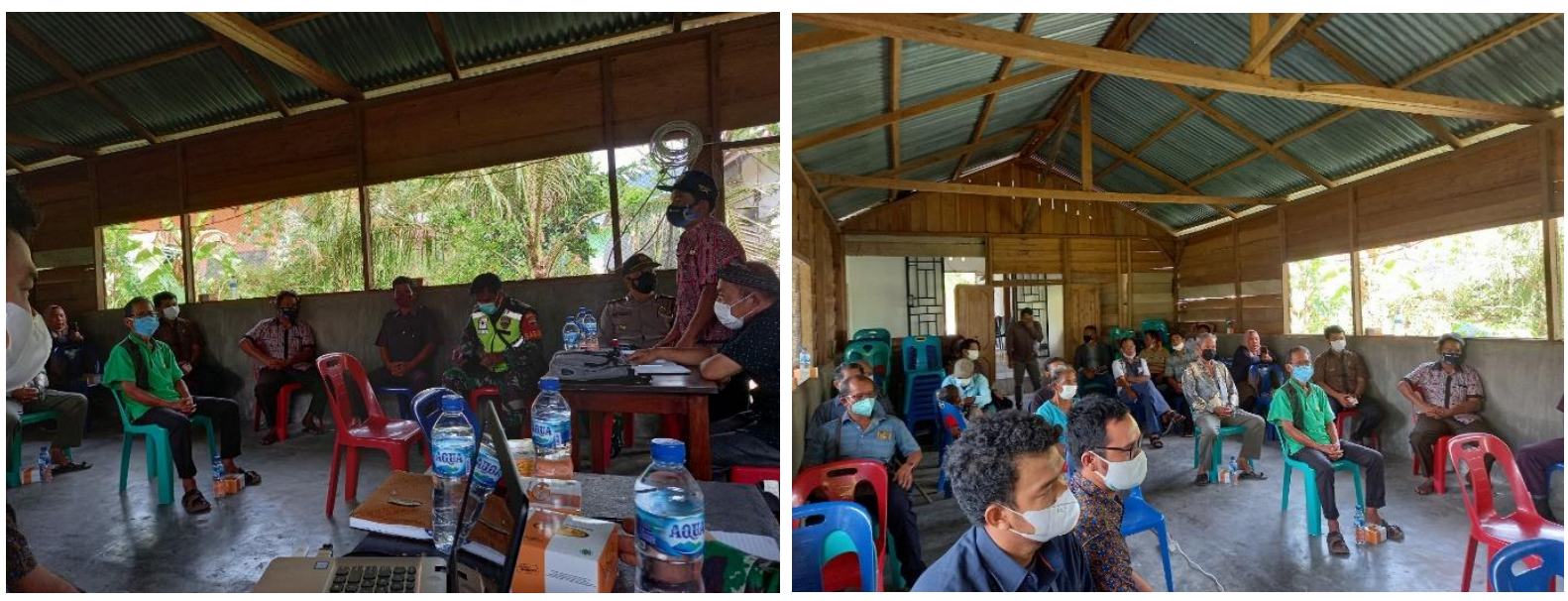

Gambar 1. Suasana kegiatan musyawarah di balai desa Meranti Utara 
Keberhasilan pengabdian ini diukur dari jumlah total masyarakat yang menerima hasil mufakat ganti rugi pemilikan hak atas tanah untuk pembangunan lebih dari $80 \%$. Kegiatan ini disudahi dengan lunasnya pemberian ganti rugi kepada masyarakat. Serta masyarakat sudah paham tentang pengelolaan keuangannya.

\section{HASIL DAN PEMBAHASAN}

Musyawarah dilaksanakan di Balai Desa Meranti Utara, kecamatan Pintu Pohon Meranti Kabupaten Toba. Yang dihadiri oleh Camat, Kades, Sekdes, Babinsa, Kanit Intel, Kapolsek, pihak PLN, Pihak PT. Surveyor Indonesia termasuk di dalamnya tim pengabdian masyarakat Universitas Tjut Nyak Dhien serta perangkat Desa dan juga masyarakat yang terdampak. Musyawarah ini di lakukan pada tanggal 29 juli 2021 dengan tujuan untuk penetapan penyelesaian terhadap teknis terhadap tanah, bangunan, atau tanaman yang dikuasai masyarakat pada Kawasan hutan dalam rangka pembangunan tapak tower untuk jaringan transmisi T/L $150 \mathrm{KV}$ Asahan 3 - Gardu induk Simangkuk.

Tim pengabdian masyarakat Universitas Tjut Nyak Dhien turut membantu kelancaran acara musyawarah. Selain musyawarah mendengarkan sosialisasi dari pembicara. Kami selaku tim pengabdian masyarakat melakukan sosialisasi personal terhadap masyarakat pemilik tanah. Hal ini dilakukan untuk meyakinkan masyarakat dan memberikan pemahaman kepada masyarakat akan pentingnya pembangunan ini. Selain itu kami juga memberikan solusi dan ide-ide kepada masyarakat tentang pemanfaatan dana yang telah diterima oleh masyarakat dari pelepasan tanah agar berguna bagi masyarakat yang terdampak pembangunan tapak tower. Beberapa kendala yang dihadapi setelah musyawarah antara lain:

1. Masih ada masyarakat yang menolak harga ganti kerugian/penyelesaian yang telah ditetapkan

2. Lahan yang dibebaskan masih memiliki sengketa dari beberapa pihak.

Solusi yang kami tawarkan adalah melakukan pendekatan kepada masyarakat melalui pendekatan personal, budaya, nonformal serta kearifan lokal setempat, dan juga melakukan pendekatan kepada tokoh-tokoh masyarakat setempat. Hasil yang kami peroleh setelah melaksanakan kegiatan tersebut adalah masyarakat yang menolak telah bersedia menerima harga ganti kerugian yang disepakati Bersama. Dan untuk lahan yang masih sengketa maka diajukan ke pengadilan.

Pelaksanaan ganti rugi/ penyelesaian teknis dilaksanakan bersamaan dengan pelepasan hak oleh pihak yang berhak. Pembayaran ganti rugi/penyelesaian teknis dilaksanakan dengan cara transfer rekening pihak yang berhak setelah pemilik lahan/kuasa menandatangani berkas administrasi pembayaran oleh PT PLN (persero) kepada pihak yang berhak melalui konsultan (PT Surveyor Indonesia).

Kegiatan pengabdian masyarakat ini dapat dikatakan berhasil. Karena 90\% pemilik tanah sudah mendapatkan uang ganti ruginya. Sisanya adalah tanah yang memiliki sengketa dan penyelesaiannya diajukan ke pengadilan. Dan juga masyarakat sudah memahami pengelolaan keuangannya setelah merima hasil ganti rugi tersebut.

\section{KESIMPULAN}

Dari hasil sosialisasi maka dapat dirangkumkan secara garis besar bahwa masyarakat memahami dengan baik maksud dari tujuan penyediaan tanah bagi kepentingan umum, ganti rugi pelepasan hak tanah sudah sesuai diantara kedua belah pihak. Serta pemahaman masyarakat mengenai masalah pengelolaan keuangan sudah baik. Secara umum proses pengalihan tanah dari masyarakat untuk pengadaan lahan tapak Tower T/L 150 KV PLTA Asahan III- Gardu Induk Simangkuk di desa Meranti utara telah berjalan dengan baik. Masyarakat yang melepaskan hak atas 
tanahnya telah mendapat ganti rugi yang layak sesuai dengan amanat dari UU no. 2 tahun 2012 tentang pengadaan lahan untuk kepentingan umum.

\section{UCAPAN TERIMA KASIH}

Kami selaku Tim pengabdian masyarakat Universitas Tjut Nyak dhien Medan mengucapkan Terimakasih kepada PT. Surveyor Indonesia dimana telah memberikan kesempatan kepada kami untuk melakukan pengabdian masyarakat yang tujuannya untuk membantu kelancaran pembangunan di Indonesia khususnya pengadaan lahan untuk pembangkit Listrik tenaga Air. Disini kami telah dipercaya untuk terlibat langsung dalam kegiatan musyawarah dan sosialisasi penetapan harga pada pekerjaan Inventarisasi dan identifikasi lahan tapak tower T/L 150 KV PLTA Asahan III - Gardu Induk Simangkuk di desa Meranti utara.

\section{REFERENSI}

Irawan, I. (2014). Studi Kasus Pembebasan Tanah Dalam Proyek Normalisasi Waduk Pluit Ditinjau Dari Perspektif Hukum Agraria. Humaniora, 5(2), 1168-1176.

Lova, E. F. (2016). Pengadaan Tanah Dalam Pembangunan Infrastruktur Jalan Tol oleh Badan Usaha Milik Negara (Persero) [Universitas Brawijaya Malang]. In Universitas Brawijaya. https://media.neliti.com/media/publications/119247-ID-none.pdf

Mengi, S. W. M. (2021). Problematika Pembebasan Tanah Dalam Rangka Pembangunan Jalan Tol Manado - Bitung. Jurnal Politico, 10(3), 1-12.

Peraturan Presiden Nomor 36 Tahun 2005 tentang Pengadaan Tanah bagi Pelaksanaan Pembangunan untuk Kepentingan Umum.

Peraturan Presiden Nomor 65 Tahun 2006 tentang Perubahan Atas Peraturan Presiden Nomor 36 Tahun 2005 tentang Pengadaan Tanah bagi Pelaksanaan Pembangunan untuk Kepentingan Umum.

Undang-Undang Nomor 2 Tahun 2012 Tentang Pengadaan Tanah Bagi Pembangunan Untuk Kepentingan Umum.

Rachmawati, I. D., \& Handoyo, P. (2014). Konflik Sosial Warga Pereng Akibat Pembebasan Lahan Tol Sumo Di Sidoarjo. Paradigma, 2(3). https://jurnalmahasiswa.unesa.ac.id/index.php/paradigma/article/view/9480/9374

Sidauruk, H. (2018). Tanah Untuk Kepentingan Umum. Kppip.Go.Id. https://kppip.go.id/opini/tanah-untukkepentingan-umum/

Sony. (2014). Pembebasan Lahan, Masih Jadi Kendala Pembangunan Infrastruktur. Pu.Go.Id. https://pu.go.id/berita/pembebasan-lahan-masih-jadi-kendala-pembangu nan-infrastruktur

Wibowo, S. N., Pujiwati, Y., \& Rubiati, B. (2021). Kepastian hukum ganti kerugian pengadaan tanah bagi pembangunan jalan tol cisumdawu. ACTA DIURNAL Jurnal IImu Hukum Kenotariatan, 4(2), 191-209.

Wirabrata, A., \& Surya, T. A. (2011). Masalah kebijakan dalam pengadaan tanah untuk pembangunan infrastruktur. Jurnal Ekonomi \& Kebijakan Publik, 2(2), 729-752. 